LEADERSHIP, 2(1), Desember 2020, ISSN (online) : :2715-0399 I

ISSN (Print out) : 2721-7108

Homepage : http://e-journal.staima-alhikam.ac.id/index.php/mpi

DOI : : : : $\quad$ : $\quad$ R2478/leadership.v2i1. 588

Article type : Review Article

\title{
IMPLEMENTASI MANAJEMEN KONFLIK DALAM PENYELESAIAN MASALAH PEMBELAJARAN DI MI AL QURAN SINGOSARI MALANG
}

\author{
Akhmad Fakhrur Rozi \\ STAI Ma'had Aly Al-Hikam Malang, Indonesia
}

\begin{abstract}
The Teghnologis Graming such a fast and modern in Madrasah Ibtidaiyah Al Quran Singosari Malang was the one of the departement. Either an educational formal and non formal in the islamic boarding school. for answering chace of global the need insight of the word science or heaven. this school the location at $\mathrm{Jl}$ ronggowuni candirenggo singosari malang upcoming MI Al Quran the vanture to be school cumate of calm. of need the one methode or conflict of management. the implementation of management to conflict can creat condusife or relationship and culture honour of diversity, can accept critice for of change the honour of another also the creat communication can be opened with to reel a patient.
\end{abstract}

This Reseach was The Qualitatif deeply sharp study cacus. the procedure was taking of data at either observation, interview, and documentation. the analysis data are insed 1. union of data 2. condentation data 3. giving of data 4. verivication. the check original data were credibility and dependability.

The goal this research was 1. knowing the implementation conflict of management in MI Al Quran Singosari Malang 2. knowing mandatory head school deeply implementation conflict of management.

140 Email Addres: Rozi_fathur@yahoo.com

LEADERSHIP: Jurnal Mahasiswa Manajemen Pendidikan is licensed under The CC BY License (https://creativecommons.org/licenses/by-sa/4.0/ ) 
LEADERSHIP, 2(1), Desember 2020, ISSN (online) : :2715-0399 I

ISSN (Print out) : 2721-7108

Homepage : http://e-journal.staima-alhikam.ac.id/index.php/mpi

DOI : : 10.32478/leadership.v2i1. 588

Article type : Review Article

The conclution was the management conflict at MI Al Quran Singosari Malang the ware not violation. but discoveret the communication between school hear with in teacher another depply to done to confict in the school.

Keywords : Implementation, conflict, learning

\begin{abstract}
Abstrak
Seiring dengan berkembangnya teknologi yang sangat cepat dan serba canggih Madrasah Ibtidaiyyah Al Qur'an Singosari merupakan salah satu lembaga yang mengkolaborasikan antara pendidikan formal dan Pesantren anak usia dini, demi menjawab tantangan global yang membutuhkan wawasan keilmuan yang sangat mumpuni dibidang duniawi maupun ukhrowi. Berada di Jl Ronggowuni kelurahan Candirenggo kecamatan Singosari MI Al Qur'an berupaya Untuk menjadikan suasana sekolah lebih kondusif, dibutuhkan suatu metode atau cara dalam mengelola konflik. Implemetasi manajemen konflik ternyata mampu menciptakan hubungan kerja yang kondusif dengan melestarikan budaya saling menghargai perbedaaan, mau menerima kritikan yang bersifat masukan untuk kebaikan, saling menghargai dan menjaga satu sama lain, serta mewujudkan komunikasi terbuka dengan penuh keikhlasan.

Penelitian ini adalah penelitian kualitatif dengan model penelitian lapangan atau studi kasus. Proses pengumpulan data yang digunakan adalah observasi, wawancara, dan dokumentasi. Adapun analisis data yang digunakan dengan cara 1). Pengumpulan data, 2). Kondensasi data, 3). Penyajian data dan 4). Verivikasi. Pengecekan keabsahan data yang digunakan adalah Credibility dan dependability.

Tujuan dari penelitian ini adalah 1). Mengetahui Implementasi Manajemen Konflik Di MI Al Qur'an Singosari Malang 2) Mengetahui Peran Kepala Sekolah dalam Mengoptimalkan Penerapan Manajemen Konflik.

Penelitian yang saya lakukan ini mendapatkan hasil sebagai berikut 1) Manajemen Konflik di MI Al Qur'an Singosari
\end{abstract}


LEADERSHIP, 2(1), Desember 2020, ISSN (online) : :2715-0399 I

ISSN (Print out) : 2721-7108

Homepage : http://e-journal.staima-alhikam.ac.id/index.php/mpi DOI : : : : $\quad$ : $\quad$ R2478/leadership.v2i1. 588

Article type : Review Article

Malang secara tertulis dan terprogram tidak ada, akan tetapi Adanya komunikasi antara Kepala Sekolah dengan para bawahanya didalam mengatasi setiap masalah yang sedang terjadi di sekolah serta pemanfaatan manajemen konflik dengan meninjau perkara yang berkaitan dengan karakter setiap individu 2) Kepala sekolah berkomunikasi dengan para bawahanya serta Konflik diselesaikan dengan melibatkan pihak-pihak yang terkait konflik didalamnya serta Adanya hubungan yang baik antara guru dan siswa, yang mana guru selalu menjalin komunikasi yang baik kepada para siswanya.

Kata Kunci: Implementasi, Konflik, Pembelajaran

\section{A. PENDAHULUAN}

Adanya konflik merupakan bagian dari kehidupan dan peradaban manusia yang memiliki model bermacam-macam. Setiap manusia mempunyai perbedaan jenis kelamin, strata sosial dan ekonomi, model hukum, suku, bangsa, kepercayaan, agama, budaya, aliran politik dan visi misi dalam mengarungi kehidupan. dalam perkembagan peradaban umat manusia, perbedaan inilah yang pasti memunculkan konflik. Selagi terdapat perbedaan yang muncul, konflik tidak dapat dihindari dan pasti akan selalu muncul. ${ }^{1}$

Konflik bisa timbul antara individu-individu, kelompok-kelompok, dan antara organisasi-organisasi. Apabila terdapat individu yang sama-sama berpegang teguh pada pandangan yang saling berkontradiksi tanpa ada titik temu kemudian mengambil kesimpulan yang berbeda dan codong bersifat intoleran, maka sangat bisa diprediksi akan muncul konflik tertentu. ${ }^{2}$

Clinton mendefinisikan tentang konflik, seperti yang dikutip oleh Kartini Kartono, konflik merupakan relaksi-relaksi Psikologis yang antagonis, berhubungan dengan maksud-maksud yang tidak biasa disamakan interesintres yang langsung dan sulit untuk ditemukan, perilaku emosional yang tidak bersahabat dan struktur nilai yang tidak sama. Dalam segi perilaku konflik bisa berwujud pertikaian halus, terkontrol, tersembunyi dan secara tidak spontan

\footnotetext{
${ }^{1}$ Wirawan, Konflik dan Manajemen Konflik; Teori, Aplikasi Dan Penelitian, Salemba Humanika, Jakarta,2010

${ }^{2}$ Winardi, Manajemen Konflik, (Konflik Perubahan Dan Pengembangan), Mandar Maju, Bandung, 2007, cet. Ke-2, Jilid 2, hlm.3.
} 
LEADERSHIP, 2(1), Desember 2020, ISSN (online) : :2715-0399 I

ISSN (Print out) : 2721-7108

Homepage : http://e-journal.staima-alhikam.ac.id/index.php/mpi

DOI : : : : $\quad$ : $\quad$ Review Article

Article type : Review Article

atau bisa sampai pada sikap yang berupa perlawanan terbuka, dan sikap ekstrim lainnya. ${ }^{3}$

Selama ini konflik muncul sebatas terjadi pada peristiwa-peristiwa yang diprediksi sudah benar-benar darurat dalam pengertian konflik memamng berada pada keadaan emosional yang klimaks, konflik bisa diterjemahkan sebagai keadaan yang sangat merusak keseimbangan organisasi atau suatu lembaga. Konflik dan pertengkaran merupakan suatu hal yang terhindarkan pada setiap organisasi sosial. Terkait definisi kata konflik itu ada banyak, salah satunya adalah menurut Lewis yaitu perbedaan perbedaan terkait nilai-nilai atau tuntutan berkenaan dengan status, kuasa dan sumbersumber lain yang bertentangan bukan hanya bertujuan agar mendapatkan sesuatu yangakan dicapai, akan tetapi juga memarjinalkan, merusak dan merugikan lawan mereka, disebutkan pula bahwa pertikaian atau konflik bisa terjadi antar individu-individu, kelompok-kelompok atau antar individu dengan kelompok. ${ }^{4}$

\section{B. METODE PENELITIAN}

Jenis penelitian ini adalah penelitian lapangan. Penelitian ini dilaksanakan dengan mengambil data-data yang ada di lapangan mengenai hal hal yang diteliti, yaitu Implementasi manajemen Konflik dalam penyelesaian masalah di MI Al Qur'an Singosari Malang

Penelitian ini termasuk jenis penelitian kualitatif dan menggunakan pendekatan studi kasus

Dalam mengumpulkan data-data yang dibutuhkan penulis, penulis menggunakan cara observasi, wawancara mendalam dan dokumentasi. Datadata yang sudah terkumpul kemudian dianalisis datanya menggunakan triangulasi data dan tahap terakhir mengambil kesimpulan

\section{LITERATURE REVIEW}

1. Implementasi Manajemen Konflik

a. Pengertian Manajemen

\footnotetext{
${ }^{3}$ Kartini Kartono, Pemimpin dan Kepemimpinan, Rajawali Press, Jakarta, 1992, hlm.213

${ }^{4}$ Lewis A Coser, George Ritzer Douglas J.Goodman, Teori Sosial Moderen, 2007, 145
} 
LEADERSHIP, 2(1), Desember 2020, ISSN (online) : :2715-0399 I

ISSN (Print out) : 2721-7108

Homepage : http://e-journal.staima-alhikam.ac.id/index.php/mpi

DOI : : : : $\quad$ : $\quad$ R2478/leadership.v2i1. 588

Article type : Review Article

Manajemen bisa dijabarkan melalui banyak cara. Mary parker Follet, salah satu tokoh ilmuan manajemen, seperti halnya dikutip oleh Mahmud M Hanafi yang mengartikan manajemen sebagai suatu seni untuk mendapatkan sesuatu yang diharapkan melalui perantara orang lain. Adanya pengertian tersebut, manajemen tidak mengharapkan seseorang bekerja dengan individualisme akantetapi harus melibatkan orang lain untuk mencapai sesuatu yang diharapkan. ${ }^{5}$

Allah juga menyuruh manusia untuk senantiasa merencanakan dan mengatur segala sesuatu yang akan dikerjakannya. Allah berfirman dalam Al-Qur'an Surat Al-Hasyr ayat 18:

Artinya:"Hai orang-orang yang beriman, bertakwalah kepada Allah dan hendaklah setiap diri memperhatikan apa yang telah diperbuatnya untuk hari esok (akhirat);dan bertakwalah kepada Allah, Sesungguhnya Allah Maha mengetahui apa yang kamu kerjakan.

b. Pengertian Manajemen Konflik

Manajemen Konflik adalah sebuah refleks dan sikap antara pelaku maupun obyek luar dalam sebuah konflik. Manajemen Konflik juga termasuk pendekatan yang mengacu pada proses yang menunjukkan pada bentuk komunikasi (termasuk perilaku) dari pelaku maupun obyek luar bagaimana cara mereka mempengaruhi kepentingan (interrest) dan interpretasi. Sedangkan bagi obyek luar menjadi pihak ketiga, yang dibutuhkannya adalah sejumlah informasi yang benar dan tepat tentang situasi dan kondisi konflik. Hal ini karena komunikasi berlangsung sempurna diantara subyek dapat terlaksana bila ada kepercayaan terhadap pihak ketiga.

2. Pengertian Pendekatan Manajemen Konflik

Pendekatan manajemen konflik bisa diartikan sebagai suatu pelaksanaan pendekatan dalam menghadapi sejumlah konflik yang terjadi dilingkungan peserta didik. Hal ini bertujuan agar peserta didik mampu berfikir cerdas dan kreatif dalam hal yang menyangkut kehidupan sehari-hari. setiap tingkah laku mereka, Bukan hanya itu, dengan munculnya pendekatan manajemen konflik, besar harapan peserta didik mampu lebih cepat berkomunikasi sempurna

\footnotetext{
${ }^{5}$ Mahmud M. Hanafi, Manajemen (Jogjakarta:UUP AMP YKPN, 1997)hlm.6 144
} 
LEADERSHIP, 2(1), Desember 2020, ISSN (online) : :2715-0399 I

ISSN (Print out) : 2721-7108

Homepage : http://e-journal.staima-alhikam.ac.id/index.php/mpi

DOI : : : : $\quad$ : $\quad$ : $2478 /$ leadership.v2i1. 588

Article type : Review Article

antar teman, sehingga tidak adalagi permasalahan dan kelompok-kelompok individual diantara mereka.

\section{HASIL DAN PEMBAHASAN}

Penyelesaian konflik (Conflict resolution) yaitu langkah yang dilaksanakan pimpinan organisasi dalam menindaklanjuti elemen-elemen yang terlibat konflik. Setiap pemimpin mempunyai model tersendiri dalam menanggapi konflik.seperti yang telah dipaparkan Tri Yudha Febrianto bahwa :

Dalam penyelesaian konflik di MI Al Qur'an Singosari ini melibatkan kepala sekolah untuk mencari solusi, bilamana konflik termasuk dalam sekala kecil maka disini diperlukan penanganan awal yakni guru mata pelajaran bila konflik tergolong serius atau guru tersebut belum menemukan solusi maka konflik tersebut dilaporkan kepala sekolah untuk mencari solusi dan tentunya kepala sekolah tidak sendirian dalam menangani atau mencari solusi ada banyak guru yang turut membantu dalam dalam menanganinya. ${ }^{6}$

Hal itu senada dengan apa yang di ungkapkan oleh dodik santoso bahwa :

Sebagai lembaga yang notabene alumnus pesantren maka sangatlah familiar dengan yang namanya musyawarah dan ringan tagan, bila salah satu guru menedapati muridnya atau bahkan dirinya sendiri mengalami konflik maka tak segan ada guru lain yang turut membantu dalam menyelesaikan masalah yang sedang dihadapi. Bila konflik belum bisa teratasi maka diperlukan peran kepala sekolah untuk mengadakan forum rapat guna membahas persoalan yang sedang dihadapi guru atau siswa yang bersangkutan. ${ }^{7}$

Memang dalam kenyataannya peneliti melihat adanya rasa kekeluargaan yang sangat erat diantara para guru dengan kepala sekolah yang mana notabene mereka alumnus pesantren, sudah menjadi hal wajib bilamana mereka saling membantu rekan yang mengalami masalah. dalam hal ini peneliti menyimpulkan bahwa MI Al Qur'an Singosari menerapkan metode kompromi dan bekerja sama dalam menyelesaikan konflik. ${ }^{8}$

\footnotetext{
${ }^{6}$ Wawancara Dengan Tri Yudha Febrianto Guru MI Al Qur'an Singosari 23 Juli 2020

${ }^{7}$ Wawancara Dengan Dodik Santoso MI Al Qur'an Singosari 23 Juli 2020

${ }^{8}$ Dokumnetasi kegiatan MI Al Qur'an Singosari
} 
LEADERSHIP, 2(1), Desember 2020, ISSN (online) : :2715-0399 I

ISSN (Print out) : 2721-7108

Homepage : http://e-journal.staima-alhikam.ac.id/index.php/mpi

DOI : : : : $\quad$ : $\quad$ Review Article

Article type : Review Article

1. Peran Kepala Sekolah Dalam Implementasi Manajemen Konflik

Kepala sekolah sebagai pimpinan lembaga memiliki tanggung jawab mengayomi dan mensejahterakan organisasi yang diembannya. seperti halnya dalam menangani konflik dan stress dalam lembaga pendidikan yaitu: (1) Menjelaskan kewajiban setiap elemen lembaga pendidikan Islam yang sesuai dengan job description; (2) Menjelaskan kepada setiap elemen lembaga supaya bekerja dengan teliti, dapat diandalkan dan dipercaya serta meminta saran kepada rekan kerja atau pimpinan bilamana terdapat konflik yang berkaitan dengan organisasi (3) Memberi saran kepada para guru agar bertaqwa serta mendekatkan diri kepada Allah SWT, agar terhindar dari konflik dan stress; (4) Memberi saran kepada para guru agar senantiasa menjunjung tinggi rasa persaudaraan dan saling menghormati antar sesama anggota lembaga dan (5) Memberi saran kepada para guru agar selalu optimis atas apa yang akan tertadi dan yang telah berlalu serta bersyukur atas nikmat yang diterima. selain itu juga untuk mengatasi konflik fan stres pimpinan atau kepala sekolah mengasah diri dalam tiga hal yakni : manajemen waktu, mengembangkan energi, dan memecahkan masalah. ${ }^{9}$

\section{a. Sebagai Motivator}

Sangatlah Mustahil bagi kepala sekolah tidak mengalami konflik yang dihadapi, terlebih jika baru menerima amanah tersebut. maka dari itu kepala sekolah harus bisa berperan aktif sebagai motivator di lembaganya, harus mengerti dan mengontrol keluhan serta konflik yang dialami oleh tenaga pendidik dan kependidikan agar mereka bisa menjalankan amanahnya dengan baik. Seringkali problem tenaga pendidik berurusan dengan pembelajaran, kewajiban pembelajaran yang terlalu berat, disiplin peserta didik, kurangnya kekompakan antar guru, dan konflik kecil yang bersifat.

\section{b. Sebagai Penengah}

Sama Halnya dengan peran kepala sekolah sebagai motivator, sebagai penengah dari konflik kepala sekolah melakukan hal yang sebagaimana dijelaskan oleh Moh Yunus sebagai berikut :

Layaknya seorang bapak dalam keluarga kepala sekolah sering kali dihadapkan dengan bermacam problematika organisasi tiap harinya, baik problem intrenal

${ }^{9}$ Dokumnetasi Peran kepala sekolah MI Al Qur'an Singosari 
LEADERSHIP, 2(1), Desember 2020, ISSN (online) : :2715-0399 I

ISSN (Print out) : 2721-7108

Homepage : http://e-journal.staima-alhikam.ac.id/index.php/mpi

DOI : : : : $\quad$ : $\quad$ Review Article

Article type : Review Article

maupun eksternal, bila mendapati ada gesekan maupun cekcok antar pribadi guru maka hal yang pertama kali dilakukan kepala sekolah adalah mempertemukan kedua belah pihak untuk mencari inti permasalahan dan solusi. ${ }^{10}$

Kepala sekolah mengklarisifikasi gejala konflik dengan jelas, hal ini sejalan dengan penjelasan kepala sekolah, selanjutnya menurut dewan guru yang berjumlah tiga orang mengemukakan benar adanya klarisifikasi gejala konflik dengan jelas. Hal ini sejalan dengan ungkapan Muklis Chusen bahwa :

Tahap awal prosedur implementasi manajemen konflik berupa identifikasi gejala konflik dengan melihat gejala-gejala yang mengikutinya"

Misalnya adanya pihak yang saling bertentangan, adanya pihak-pihak yang berinteraksi saling berlawanan. Selanjutnya berdasarkan analisis hasil wawancara "benar adanya indikasi konflik dimana terjadi pertentangan dan berlawanan dalam berinteraksi antara satu pihak dan pihak lain"11

\section{c. Sebagai Pengelola Waktu}

Sudah Selayaknya kepala sekolah membiasakan diri untuk memanajemen waktunya, karena banyak waktu yang sering tersita tanpa ada tujuan dan kegunaan yang jelas. Hal ini disebabkan oleh rentetan jadwal kegiatan administrative yang sulit diatur, berbeda dengan kegiatan pembelajaran.

Sangat jarang sekali kepala sekolah menggunakan waktunya untuk kepentingan pribadi, kepala sekolah diharuskan bisa membagi waktu dengan peserta didik, orang tua peserta didik, tenaga kependidikan, tokoh masyarakat, lembaga swadaya masyarakat, dinas pendidikan, bahkan mungkin tamu tidak diundang yang sering datang ke sekolah. kerapkali tenaga kependidikan meminta waktu guna mengutarakan keluhannya saat kepala sekolah sudah siap untuk pulang dan percakapan yang berlarut malam.

\section{d. Sebagai Pemecah Masalah}

Sangat sering permasalahan yang dihadapi kepala sekolah, terlebih lagi bila baru menduduki jabatan tersebut. maka dari itu kepala sekolah harus bisa pro

\footnotetext{
${ }^{10}$ Wawancara dengan Moh Yunus Guru Madrasah Ibtidaiyyah Al Qur'an Singosari Malang

${ }^{11}$ Wawancara dengan Muklis Chusen kepalaMadrasah Ibtidaiyyah Al Qur'an Singosari Malang
} 
LEADERSHIP, 2(1), Desember 2020, ISSN (online) : :2715-0399 I

ISSN (Print out) : 2721-7108

Homepage : http://e-journal.staima-alhikam.ac.id/index.php/mpi

DOI : : : : $\quad$ : $\quad$ Review Article

Article type : Review Article

aktif berperan sebagai penopang di sekolahnya, harus menyerap dan memahami keluhan serta konflik yang dialami oleh para guru agar mereka dapat melaksanakan tugas dengan baik.

\section{E. Kesimpulan}

Berdasarkan pemaparan hasil pembahasan dan analisis data pada bab sebelumnya, maka penelitian ini dapat ditarik kesimpulan sebagai berikut :

1. Implementasi manajemen konflik yang dilakukan oleh kepala Madrasah Ibtidaiyyah Al Qur'an Singosari sudah berjalan sangat baik dalam faktor penyelesaian konflik yang terjadi di sekolah. Dalam penyelesaian konflik di MI Al Qur'an Singosari ini melibatkan kepala sekolah guna menemukan solusi, apabila konflik dalam kategori sekala kecil maka dibutuhkan penanganan awal yakni guru mata pelajaran, bila konflik tergolong serius maka konflik tersebut diserahkan kepala sekolah untuk menemukan solusi.

2. Metode Kepala Sekolah dalam mengelola manajemen konflik di MI Al Qur'an Singosari ialah dengan berusaha membangun komunikasi dengan baik dan mempelajari hal-hal yang berkaitan dengan sifat setiap individu, karena sifat setiap individu berbeda-beda di sekolah. dan juga mengadakan buku kejadian untuk para siswa sebagai alternatif lain demi menciptakan suasan yang kondusif dan nyaman.

\section{F. REFERENSI}

Abu, Achmad. Cholid Narbuko. 2007 Metodologi Penelitian. Jakarta: Bumi Aksara.

Arikunto, Suharsini.2003. Prosedur Penelitain Suatu Pendekatan Praktek. Cetakan 11.Jakarta: Rineka Cipta.

Hanafi, M Mahmud.1997. Manajemen, Jogjakarta UUP AMP YKPN.

Handoko, T Hani Handoko.1984. Manajemen. BPFE. Yogyakarta.

Kartini, Kartono.1992. Pemimpin dan Kepemimpinan. Jakarta: Rajawali Press. Lexi J. Moleong. 2009. Metodologi Penelitian Kualitatif, Bandung. Remaja Rosdakarya.

Mahfud, Chairul. 2010. Pendidikan Multikultural. Yogyakarta: Pustaka pelajar. Suprayogo, Imam dan Tabroni. 2003 Metode Penelitian Sosial dan Agama, Bandung : Remaja Rosda Karya.

Sunardi, Dono. 2009 Manajemen Strategi Konsep. Jakarta : Salemba Empat. 
LEADERSHIP, 2(1), Desember 2020, ISSN (online) : :2715-0399 I

ISSN (Print out) : 2721-7108

Homepage : http://e-journal.staima-alhikam.ac.id/index.php/mpi

DOI : : : : $\quad$ : $\quad$ Review Articleadership.v2i1. 588

Article type : Review Article

Sutrisno, Hadi. 2004 Metode Research. Yogyakarta.

S. Nasution. 2006. Metode Research (Penelitian Ilmiah), Jakarta : Bumi Aksara. Ulwan, Nashih Abdullah. 1990. Pendidikan Sosial Anak. Bandung : Remaja Osadakarya offset-Bandung.

Wirawan. Konflik dan Manajemen Konflik; Teori, Aplikasi Dan Penelitian. Jakarta : Salemba Humanika.

Winardi. 2007. Manajemen Konflik, (Konflik Perubahan Dan Pengembangan), Bandung : Mandar Maju.

Yusuf, al Aqsori. 2006. Manajemen Konflik: Bagaimana Mengatasi Masalah Dengan Orang Lain. Jakarta : Imron Affandi Robbani Press. 